\title{
Influence of an Island on Hysteresis of a Western Boundary Current Flowing across a Gap
}

\author{
HuAn MEI AND YiQUAN QI \\ College of Oceanography, Hohai University, Nanjing, China \\ Bo QIU \\ Department of Oceanography, University of Hawai'i at Mānoa, Honolulu, Hawaii \\ Xuhua Cheng and Xiangbai Wu \\ College of Oceanography, Hohai University, Nanjing, China
}

(Manuscript received 6 June 2018, in final form 13 March 2019)

\begin{abstract}
We investigate impact of an island on hysteresis of a western boundary current (WBC) flowing across a gap using a nonlinear 1.5-layer ocean model. The results of hysteresis curves show the island in the middle of the gap facilitates the WBC intrusion. The inserted (removed) island in the middle of the gap promotes the WBC to shed eddy (leap across the gap) when the WBC path transits from the periodic penetrating (leaping) to the leaping (periodic penetrating) regime without (with) an island. Vorticity balance analysis reveals that the WBC transition from the eddy-shedding (leaping) to the leaping (eddy-shedding) regime is induced by increased (decreased) meridional advection. Moreover, the critical Reynolds number of the WBC at the Hopf bifurcation is not sensitive to the size and location of the island when the total gap width is fixed. The critical Reynolds number of the WBC translating from the eddy shedding to the leaping regime increases when either the total gap width increases or the island's meridional length increases; however, the critical Reynolds number is inversely proportional to the width of the southern gap with fixed total gap width and enlarged island length. The island promotes the WBC to shed eddy except when the island is near the northern barrier. The influence of an eastward-shifted island on the WBC transition from the eddy-shedding to the leaping regime is gradually reduced when the island is east of the Munk layer.
\end{abstract}

\section{Introduction}

A western boundary current (WBC) flowing across a strait in between two islands or landmasses resembles the Kuroshio passing by the Luzon Strait and the Gulf Stream flowing from the Yucatan to the southern tip of the Florida Peninsula. When the Kuroshio passes by the Luzon Strait, the Kuroshio exhibits mainly five kinds of flow patterns, the leaping pattern, the Kuroshio branching, the anticyclonic Kuroshio loop path, the anticyclonic eddy-shedding path, and the cyclonic eddy intrusion pattern (Caruso et al. 2006). The intrusion of the Kuroshio into the South China Sea (SCS) plays an important role in the variations of temperature, salinity, circulation, and eddy generation in

\footnotetext{
Corresponding author: Yiquan Qi, qiyiquan@hhu.edu.cn
}

the northeastern SCS (Qu et al. 2000, 2004; Caruso et al. 2006; Yuan et al. 2006; Yu et al. 2007; Xiu et al. 2010; Wu 2013; Nan et al. 2015). The characteristics of the Kuroshio intrusion and the spatial-temporal variation of the currents near the Luzon Strait have been widely studied (Nitani 1972; Chern and Wang 1998; Fang et al. 1998; Hu et al. 2000; Caruso et al. 2006; Yuan et al. 2006).

Multiple flow patterns of the Kuroshio exist in the Luzon Strait according to observations (Nitani 1972; Caruso et al. 2006; Yuan et al. 2006). Figure 1 shows an eddy shedding from a Kuroshio Loop Current (KLC) using the AVISO altimeter data (http://www.aviso.oceanobs.com/). The KLC can be seen in the region southwest of Taiwan before an anticyclonic eddy was shed. The Kuroshio intruded into the SCS through the central Luzon Strait and turned around toward the Pacific in the northern 

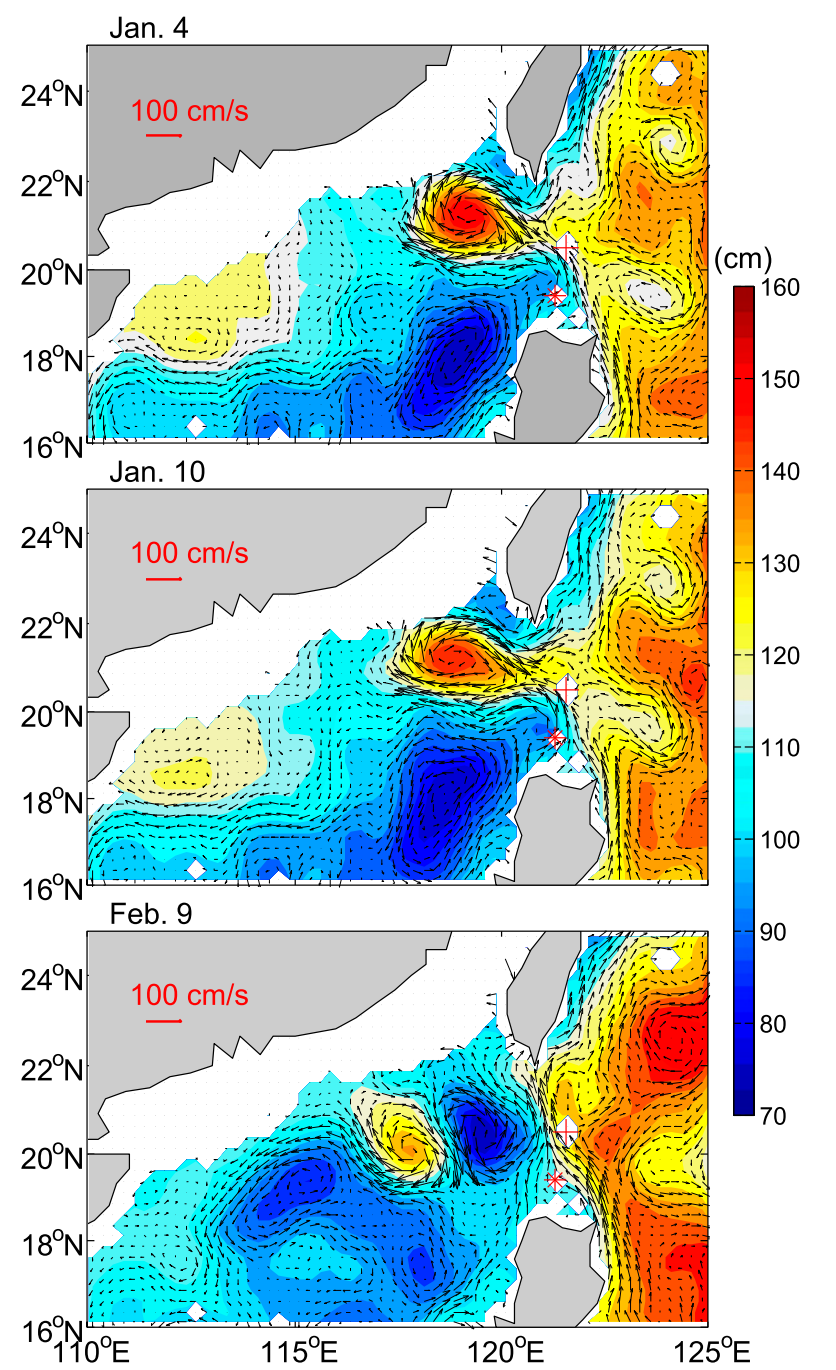

FIG. 1. Altimeter SSH (shading; $\mathrm{cm}$ ) and geostrophic currents (vectors; $\mathrm{cm} \mathrm{s}^{-1}$ ) in the northeastern SCS showing an eddy shedding from the Kuroshio Loop Current in January 2012. Regions shallower than $100 \mathrm{~m}$ are whited out. The Batanes Island chain and the Babuyan Island chain are marked by the red plus sign and asterisk, respectively.

Luzon Strait (Fig. 1, top). After the anticyclonic eddy was shed from the KLC, the Kuroshio translated from the eddy-shedding pattern to the leaping pattern (Fig. 1, bottom). More details on this event can be found in Zhang et al. (2017). Several mechanisms have been proposed to explain the Kuroshio intrusion (Zhong et al. 2016, and references therein).

The hysteresis of the WBC concerns the multiple states in the gap-leaping system. Studies have shown that the hysteresis of the $\mathrm{WBC}$, which depends on the history of the WBC evolution, exists under certain ranges of nondimensional controlling parameters (Sheremet 2001; Yuan and Li 2008; Wang et al. 2010;
Yuan and Wang 2011; Wang and Yuan 2012, 2014). Sheremet (2001) investigated hysteresis using a quasigeostrophic model in an idealized gap-leaping system, and found that the multiple flow patterns (penetrating or leaping) exist for the WBC passing by a gap. The inertia ( $\beta$ effect) promotes the leaping (penetrating) state of the WBC. The hysteresis exists when the ratio of the halfwidth of the gap to the width of the Munk boundary layer is larger than 4.55. The multiple flow patterns of the WBC have been validated by several laboratory experiments (Sheremet and Kuehl 2007; Kuehl and Sheremet 2009, 2014). Wang et al. (2010) studied the effect of meridional wind on WBC flow patterns near a gap using a shallow water equation model. Their results demonstrated that the WBC is inclined to leap across (penetrate into the western basin through) the gap when forced by the southerly (northerly) wind. Yuan and Wang (2011) studied the effects of finite deformation radii and the impingement of mesoscale eddies from the eastern basin on WBC hysteresis and paths using a quasigeostrophic model. Their results showed that both cyclonic and anticyclonic eddies can induce the WBC translation from the periodic penetrating to the leaping regime; whereas only cyclonic eddies can induce the WBC transition from the leaping to the periodic penetrating regime. The chance and duration for the WBC to leap across the gap should be about 3 times as often as to penetrate the western basin (Yuan et al. 2006). Wang and Yuan $(2012,2014)$ investigated some nonlinear dynamic problems and hysteresis of two WBCs with equal and unequal transports colliding at a gap.

It is known that a branch of the Kuroshio flows northwestward into the SCS through the Balintang Channel, and most of the Kuroshio water flows out of the SCS through the Bashi Channel (Yuan et al. 2006; Nan et al. 2011, 2015; Sun et al. 2016). In the southern regions of the two channels, there are the Babuyan Island chain and the Batanes Island chain, respectively (Fig. 1). The north-south span of each island chain exceeds $60 \mathrm{~km}$. The baroclinic deformation radius $L_{R}$ of the Kuroshio is about $50 \mathrm{~km}$ near the Luzon Strait (Chelton et al. 1998; Yuan and Wang 2011). Therefore, these island chains may affect the WBC flow pattern naturally. In fact, the local topography has significant impacts on the current path near the Luzon Strait. Using a $1 / 16^{\circ}$ Naval Research Laboratory (NRL) Layered Ocean Model (NLOM), Metzger and Hurlburt (2001) has found that both the Calayan Bank $\left(19.7^{\circ} \mathrm{N}, 121.4^{\circ} \mathrm{E}\right)$ and the shoal north of Calayan Island $\left(19.5^{\circ} \mathrm{N}, 121.5^{\circ} \mathrm{E}\right)$ reduce the westward bending of the Kuroshio path, when compared with the case where these two topography features are absent. A modeling study by Lu and Liu (2013) indicates 
that existence of a sharp northeast cape of the Philippine islands is one of the most important factors for the gapleaping Kuroshio path. In the central Luzon Strait, the Kuroshio is found to be separated into two branches as it collides with the Batanes Islands, where the western (eastern) branch carries $68 \%$ (32\%) of the Kuroshio transport. In addition, an anticyclonic (a cyclonic) mesoscale eddy approaching the Batanes Islands from the eastern basin can strongly intensify (weaken) the eastern branch of the Kuroshio (Lu and Liu 2013).

The abovementioned observations and modeling results suggest that an island plays an important role in determining the WBC path and mesoscale eddyWBC interactions in a gap-leaping system. So far, several studies investigated eddy-WBC interactions (e.g., Cenedese 2002; Simmons and Nof 2002; Herbette et al. 2003; Cenedese et al. 2005; Yuan et al. 2006; Andres and Cenedese 2013; Zhong et al. 2016). Yuan et al. (2006) reported that the anticyclonic intrusion of the Kuroshio in the Luzon Strait area is observed less than $30 \%$ of the time on average based on satellite remote sensing data. Most of the mesoscale eddies from the eastern side of the Luzon Strait passed by the gap to move northward without entering the SCS. Studies using observations (Yuan et al. 2006), idealized models (Sheremet 2001; Wang et al. 2010; Yuan and Wang 2011), and realistic models (Metzger and Hurlburt 2001; Lu and Liu 2013), however, do not fully explain the dynamics of the influence of an island on WBC flow patterns. The mechanism of an island impacting the hysteresis of the WBC in a gap-leaping system is worth studying.

In this paper, we demonstrate the influence of an island on hysteresis of a WBC using a nonlinear 1.5-layer ocean model. The remainder of the paper is organized as follows. The model configuration is described in section 2. The hysteresis of the WBC is studied with or without an island in the gap, and their dynamics are explored by using vorticity balance in section 3 . The impacts of island size and location on the bifurcation of the WBC are investigated in section 4. A summary and discussion are given in section 5 .

\section{Numerical model and method}

An idealized model basin is used, which contains two rectangular domains separated by a thin meridional barrier with a gap in the middle. The western domain covers $0^{\circ}-30^{\circ} \mathrm{N}, 100^{\circ}-120^{\circ} \mathrm{E}$ and the eastern one covers $0^{\circ}-30^{\circ} \mathrm{N}, 120^{\circ}-150^{\circ} \mathrm{E}$. The thin meridional barrier is located at $120^{\circ} \mathrm{E}$, and the gap is from $13.7^{\circ}$ to $16.3^{\circ} \mathrm{N}$.

To simplify the problems expounded in the introduction, we adopt the simple nonlinear 1.5-layer model
(Qiu and Chen 2012; Cheng et al. 2017). The governing equations are as follows:

$$
\begin{aligned}
& \mathbf{u}_{t}+\xi \mathbf{k} \times \mathbf{u}=-\nabla E+A_{h} \nabla^{2} \mathbf{u}-R \mathbf{u}+\frac{\boldsymbol{\tau}}{\rho_{0} h}, \\
& h_{t}+\nabla \cdot(h \mathbf{u})=0,
\end{aligned}
$$

where $\mathbf{u}=(u, v)$ is horizontal velocity vector, $h$ is upper-layer thickness, $\tau=\left(\tau_{x}, \tau_{y}\right)$ is wind stress vector, $\rho_{0}=1024 \mathrm{~kg} \mathrm{~m}^{-3}$ is the reference density, $A_{h}=$ $300 \mathrm{~m}^{2} \mathrm{~s}^{-1}$ is horizontal eddy viscosity coefficient, and $R=5 \times 10^{-8} \mathrm{~s}^{-1}$ is the interlayer (bottom) friction coefficient. The resting upper-layer thickness is set to $300 \mathrm{~m}$. Also, $\xi=f+\mathbf{k} \cdot \nabla \times \mathbf{u}$ is the absolute vorticity, and $E=g^{\prime} h+\left(u^{2}+v^{2}\right) / 2$ is the total energy. The reduced gravity is $g^{\prime}=0.031 \mathrm{~m} \mathrm{~s}^{-2}$. In this study, the Munk layer width $\left[L_{M}=\left(A_{h} / \beta\right)^{1 / 3}\right]$ is $24.7 \mathrm{~km}$ and the north-south width of the gap $L_{g}$ is about $290 \mathrm{~km}$, that is, $\gamma=L_{g} / 2 L_{M}$ is 5.85 , which guarantees the existence of WBC hysteresis according to Sheremet (2001).

An idealized zonal wind field is employed to drive a WBC in the eastern basin, and the transport of the WBC is controlled by the wind stress with a parameter $\alpha_{\tau}$. The wind stress is given by

$$
\tau_{x}=-\alpha_{\tau} \tau_{0} \cos \left(\frac{\pi \phi}{D_{\mathrm{N}-\mathrm{S}}}\right),
$$

where $\tau_{0}=0.1 \mathrm{~N} \mathrm{~m}^{-2}, \phi$ is latitude, and $D_{\mathrm{N}-\mathrm{S}}$ is the interval of latitude between the northern and southern boundaries. For each $\alpha_{\tau}$, the integration time of the governing equations is long enough for the WBC reaching a steady state solution. Then the transport per unit depth of the WBC (defined as $Q$ ) is calculated from the steady state solution on the zonal section from $13.7^{\circ} \mathrm{N}, 120^{\circ} \mathrm{E}$ to $13.7^{\circ} \mathrm{N}, 121^{\circ} \mathrm{E}$. The Reynolds number is defined as $\operatorname{Re}=Q / A_{h}$.

The partial differential equations of the model are solved by the finite difference method using the Arakawa $\mathrm{C}$ scheme with the energy-conserving option. The spatial resolution of the model is $0.1^{\circ}$. The nonslip boundary condition is applied at all boundaries including the barriers. The minimum upper thermocline depth is set as $25 \mathrm{~m}$.

\section{Influence of an island in the middle of the gap on WBC hysteresis}

Two numerical experiments are designed to study hysteresis of the WBC. In one case, we insert an island of about $56 \mathrm{~km}$ in width in the middle of the gap from $14.8^{\circ} \mathrm{N}$, $120^{\circ} \mathrm{E}$ to $15.3^{\circ} \mathrm{N}, 120^{\circ} \mathrm{E}$. In the other case, there is no island, which is similar to the case used in Sheremet (2001), 
but is different in terms of deformation radii $L_{R} \rightarrow \infty$ in our study and $L_{R} \rightarrow 0$ in his study.

\section{a. Hysteresis of the WBC}

Figure 2 compares the hysteresis curves of the WBC intruding into the western basin with and without the island. On the $y$ axis, $X_{P}$ represents the farthest westward distance of the $\psi=Q / 2$ streamline into the western basin. The value of $\alpha_{\tau}$ is increased gradually from 0.21 to 0.80 with the interval $\Delta \alpha_{\tau}=0.01$ (defined as the wind stress increasing stage), and then decreased to 0.21 (defined as the wind stress decreasing stage). The Reynolds number is calculated from the steady state solution for each $\alpha_{\tau}$. The latter integration is initialized by the steady state solution of the previous integration, and the historical WBC status is produced in this way as in Yuan and Wang (2011).

In the wind stress increasing stage, there exist three kinds of WBC flow patterns as Re increases (Fig. 2). At low $\mathrm{Re}$, the WBC intrudes into the western basin through the gap in a steady anticyclonic loop pattern until $R_{C, n}=30$ (no island) and $R_{C, i}=29$ (with island) for the gap without and with the island, respectively, which represents the lower Hopf bifurcation of the WBC translating from the steady penetrating to the periodic eddy-shedding regime. Then, the hysteresis curves become multivalued, and the WBC bifurcates to shed eddies. The multivalued curves represent the farthest and nearest distances of the WBC intruding into the western basin between two adjacent half periods of eddy shedding, respectively. Sheremet (2001) showed the critical Re (his notation $\operatorname{Re}_{C}$ ) of the WBC transition from the steady penetration to the periodic eddy-shedding regime increases as $\gamma$ increases under the approximation $L_{R} \rightarrow 0$. Yuan and Wang (2011) showed the similar critical $\mathrm{Re}$ (their notation $R_{\mathrm{C}}$ ) decreases as $L_{R}$ increases for a fixed $\gamma$. Note that $L_{R} \rightarrow \infty$ in our study; therefore, a moderate $R_{C, n}$ (no island) for a relatively large $\gamma$ obtained here is reasonable.

The WBC then experiences a second transition at $R_{L, n}=65$ (no island) and $R_{L, i}=74$ (with island). When $\mathrm{Re}$ is larger than the critical value, the WBC leaps across the gap and becomes steady again. Sheremet (2001) showed that the critical Re (his notation $\mathrm{Re}_{P}$ ) of the WBC transition from the periodic eddy shedding to the leaping regime increases as $\gamma$ increases. Yuan and Wang (2011) showed that similar critical Re (their notation $\mathrm{R}_{L}$ ) is not sensitive to the magnitude of deformation radius. So, for a relatively larger $\gamma$ and $L_{R} \rightarrow \infty$, the $R_{L, n}$ (no island) obtained by the present model is larger than that in Yuan and Wang (2011).

In the wind-stress-decreasing stage, the WBC keeps its leaping path until $R_{P, n}=46$ (no island) and $R_{P, i}=50$

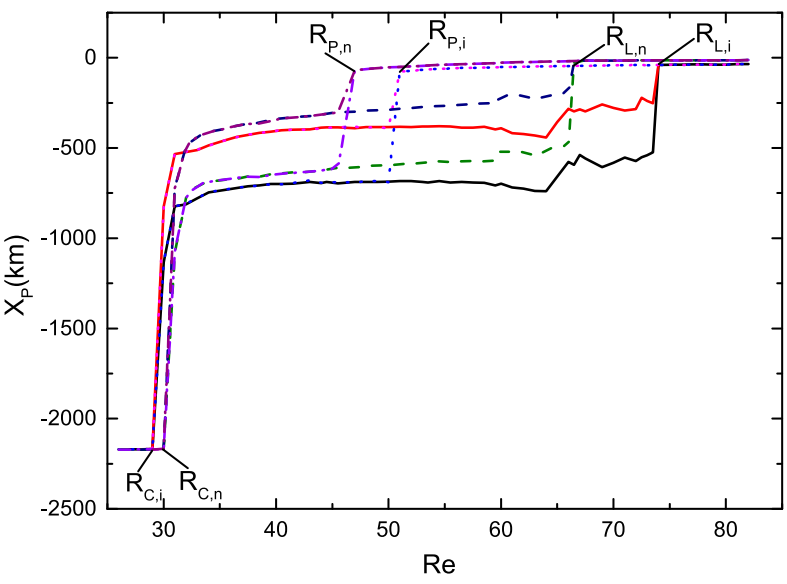

FIG. 2. Hysteresis curves of the WBC with and without an island in the gap. On the $y$ axis $X_{P}$ represents the farthest westward distance of the $\psi=Q / 2$ streamfunction of the $\mathrm{WBC}$, with 0 indicating the location of the gap. In the lower right, $R_{C, i}\left(R_{C, n}\right)$ is the critical point for the WBC with (without) an island in the gap translating from the penetrating to the eddy-shedding regime. Along the top, $R_{L, i}\left(R_{L, n}\right)$ is the critical point for the WBC with (without) an island in the gap translating from the eddy-shedding to the leaping regime, and $R_{P, i}\left(R_{P, n}\right)$ is the critical point for the WBC with (without) an island in the gap translating from the leaping to the eddy-shedding regime.

(with island). Then, the WBC translates to the eddyshedding regime. Sheremet (2001) showed that the critical $\mathrm{Re}$ (his notation $\mathrm{Re}_{L}$ ) of the WBC transition from the leaping to the periodic eddy-shedding regime decreases as $\gamma$ decreases. Yuan and Wang (2011) showed that similar critical $\operatorname{Re}$ (their notation $R_{P}$ ) is not sensitive to the magnitude of deformation radius. So, for a relatively large $\gamma$, the $R_{P, n}$ in the present model is larger than that in Yuan and Wang (2011). In contrast to the finding of Sheremet (2001), where the WBC translated directly from the leaping path to the steady penetration, our numerical experiments show that the WBC transition is from the leaping to the periodic eddyshedding regime at $R_{P, n}$ (no island) and $R_{P, i}$ (with island), similar to the result of Yuan and Wang (2011). Yuan and Wang (2011) explained that the transient evolution of the relative vorticity becomes important at low Reynolds number. In our study, the periodic eddyshedding and leaping paths of the WBC coexist for the same Re in the range of $\left(R_{P, n}, R_{L, n}\right)$ without the island and $\left(R_{P, i}, R_{L, i}\right)$ with the island.

Figure 3 shows the flow pattern evolution corresponding to WBC hysteresis with the island. Starting from a small $\mathrm{Re}=28$ (Fig. 3a), the WBC enters the western basin in a steady anticyclonic loop pattern. The solid bold contour represents the $\psi=Q / 2$ streamfunction of the WBC and the shed eddy (similarly hereinafter). At $\operatorname{Re}=30$, the solution appears in the 

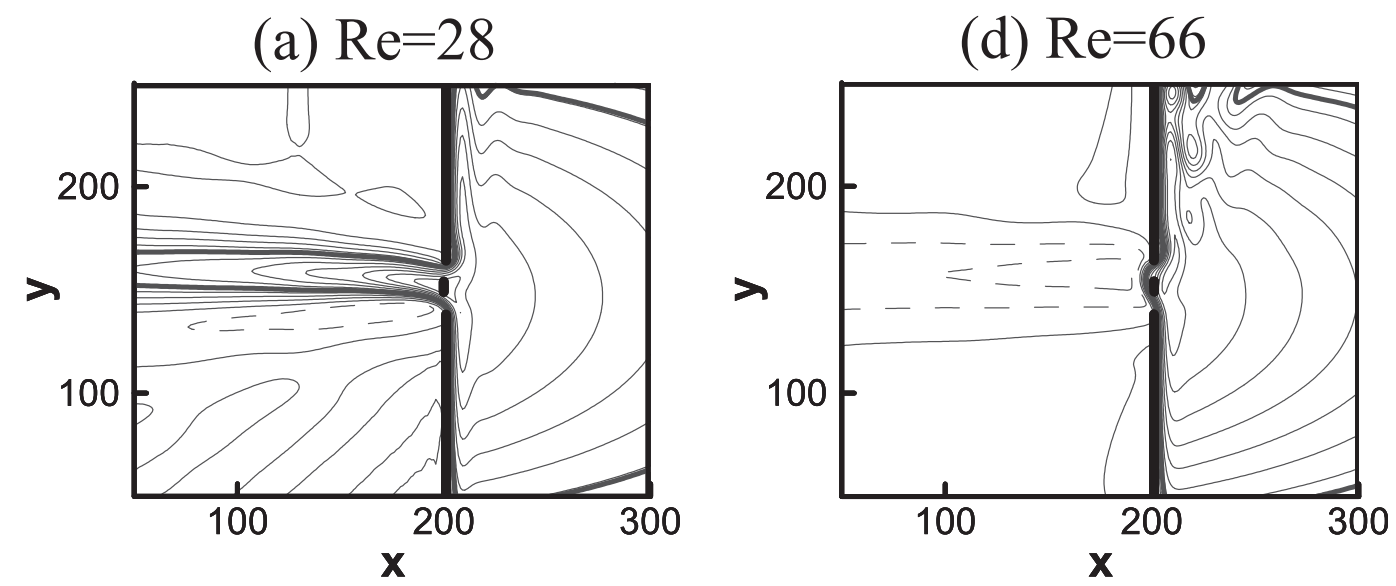

(b) $\mathrm{Re}=66$

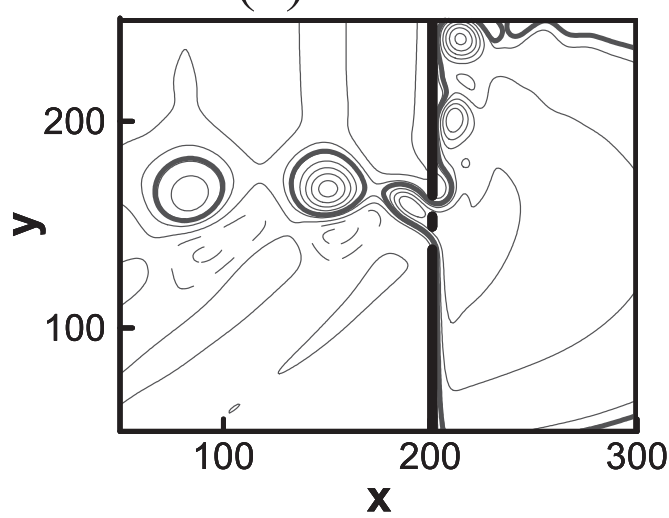

(e) $\mathrm{Re}=50$

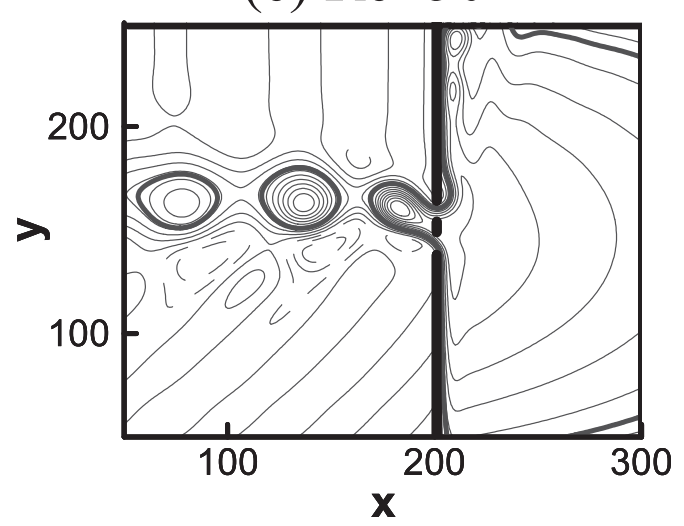

(c) $\mathrm{Re}=74$

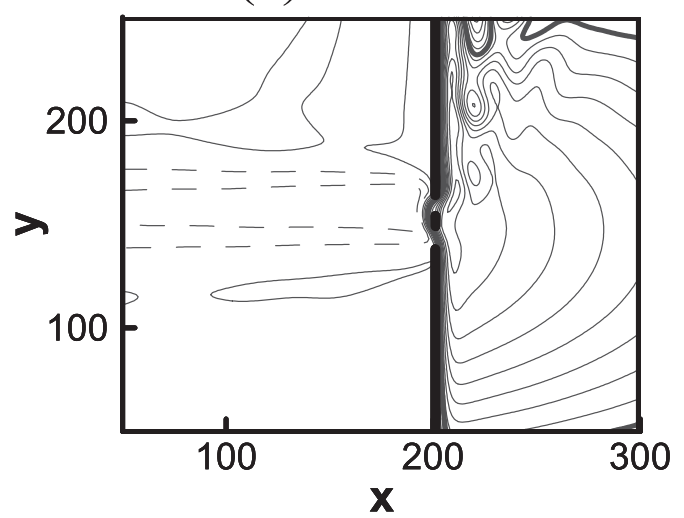

(f) $\mathrm{Re}=28$

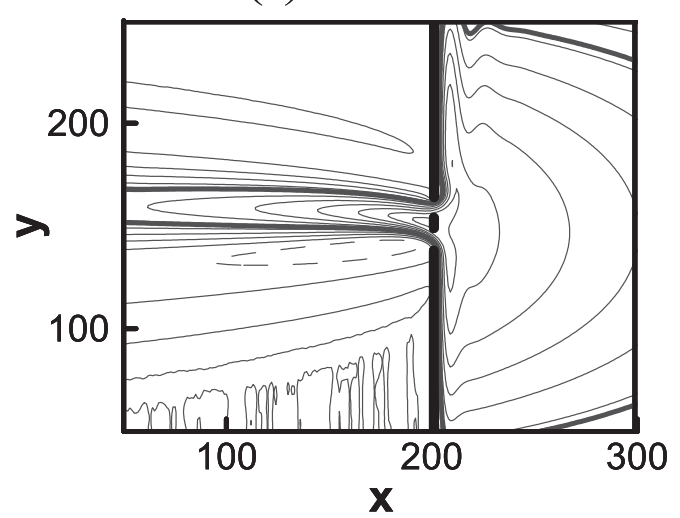

FIG. 3. Evolution of a WBC passing by a gap with an island in the middle of the gap under different Re. Columns show the WBC driven in (a)-(c) a wind stress increasing stage and (d)-(f) a wind stress decreasing stage. (c),(e) The $R_{L, i}$ and $R_{P, i}$ points in Fig. 2, respectively. The solid bold line represents the $\psi=Q / 2$ streamfunction of the WBC and the shed eddy. The solid (dashed) lines indicate negative (positive) streamfunction values.

periodic eddy-shedding pattern. The flow pattern shown in Fig. $3 \mathrm{~b}$ is at $\mathrm{Re}=66$. As the Reynolds number is increased to $\mathrm{Re}=74$ (Fig. 3c), the WBC starts to leap across the gap. The variation of WBC flow pattern in the wind stress increasing stage and the eddy shedding from the WBC are similar to the observations shown in Fig. 1. In the wind stress decreasing stage, the WBC preserves the leaping path from $\mathrm{Re}=82$ to $\mathrm{Re}=66$ (Fig. 3d). Figures $3 \mathrm{~b}$ and $3 \mathrm{~d}$ show that the flow patterns are different at the same $\mathrm{Re}=66$, which illustrates the 
importance of historical WBC evolution. When the Reynolds number is decreased to $\mathrm{Re}=50$, the transition from the leaping to the eddy-shedding path occurs (Fig. 3e). Further decreasing the Reynolds number to $\mathrm{Re}=28$, the WBC enters the western basin as an anticyclonic loop pattern (Fig. 3f).

In the wind stress increasing stage, the island in the middle of the gap facilitates the WBC intrusion into the western basin by shedding eddies compared with the no-island case (because $R_{L, i}>R_{L, n} ;$ Fig. 2). The WBC without the island translates from the periodic eddyshedding to the leaping regime at $R_{L, n}=65$, while the WBC with the island maintains the periodic eddyshedding regime at $\mathrm{Re}=65$. In the wind stress decreasing stage, the WBC with the island translates from the leaping to the eddy-shedding path at $R_{P, i}=50$, while the WBC without the island maintains the leaping path at $\mathrm{Re}=50$ (because $R_{P, n}<R_{P, i} ;$ Fig. 2). The dynamics behind the island's impact on the WBC transition will be investigated using vorticity balance analysis in section 3c.

\section{b. Critical eddy shedding-leaping state of the WBC}

Four experiments are designed to study the dynamics described in section $3 \mathrm{a}$. The setups of the experiments are listed in Table 1. For experiments (Exps) A1 and $\mathrm{A} 2$, the initial conditions are the steady state solution of the WBC without the island at $\mathrm{Re}=64$ (referred to as I.C. 1). For Exps B1 and B2, the initial conditions are the steady state solution of the WBC with the island in the gap at $\mathrm{Re}=50$ (referred to as I.C. 2).

The time evolutions of WBC flow patterns for Exp A1 (top) and Exp A2 (bottom) are shown in Fig. 4. In Exp A1, the WBC without the island translates from the eddy-shedding to the leaping path, and keeps the leaping path after day 1200 . Due to the nonlinearity of the gap flow, as shown in Sheremet (2001), the inflow part of the $\beta$ plume shifts northward and occupies the southern and central parts of the gap, and the outflow part of the $\beta$ plume is narrowed to occupy the northern part of the gap. Similarly in our numerical experiment, when the island is inserted into the gap at day 0 in Exp $\mathrm{A} 2$, the island mainly affects the inflow by blocking the WBC intrusion into the western basin (not shown). However, the WBC in Exp A2 continues to intrude into the western basin by shedding eddies, and the island facilitates the WBC intrusion.

The time evolution of WBC flow pattern near the gap for Exp B1 (top) and Exp B2 (bottom) are shown in Fig. 5. At day 0, the WBC in Exp B1 leaps across the gap, and then starts to shed eddy around day 600 during the adjustment of the decreased wind stress. The WBC henceforth stays in the periodic eddy-shedding regime
TABLE 1. List of experiments. The first column lists experimental names. The second column lists the setup of each experiment. Exps $\mathrm{A} 1$ and A2 (B1 and B2) are driven by the wind stress with $\alpha_{\tau}=0.62$ ( $\left.\alpha_{\tau}=0.44\right)$ corresponding to $R_{L, n}=65\left(R_{P, i}=50\right)$ in Fig. 2 . The Exp-G set, Exp-I set, and Exp-GI set (Exp-NS set and Exp-WE set) are used to study the influence of island north-south size (northsouth and east-west locations) on the WBC bifurcation, as defined in section 4.

\begin{tabular}{ll}
\hline \hline Experiment & \multicolumn{1}{c}{ Setup } \\
\hline Exp A1 & No island with I.C. 1 (see text) \\
Exp A2 & Inserting an island with I.C. 1 (see text) \\
Exp B1 & Keeping the island with I.C. 2 (see text) \\
Exp B2 & Removing the island with I.C. 2 (see text) \\
Exp-G set & Total gap width is variable \\
Exp-I set & Island north-south size is variable \\
Exp-GI set & Total gap width and island north-south size are \\
& variable \\
Exp-NS set & North-south location of the island is variable \\
Exp-WE set & West-east location of the island is variable \\
\hline
\end{tabular}

corresponding to the $R_{P, i}$ point in Fig. 2. Contrarily, when the island is removed from the initial field at day 0 , the WBC in Exp B2 retains the leaping path as the time elapses, which illustrates that the influence of the removed island is dominant on the WBC path compared with the adjustment of decreased wind stress in this situation.

The solutions of the four experiments reveal that the island in the middle of the gap facilitates the WBC intrusion and determines the final WBC path at the critical state. To better understand the dynamics of the island's impact on WBC flow pattern, the vorticity balance of the WBC is investigated next.

\section{c. Vorticity balance of the WBC}

The WBC path is determined by the vorticity balance among inertial term, viscosity term, and beta term in the steady-state solution, as pointed out by Yuan and Wang (2011), which has no island in the gap. According to the conceptual model of Sheremet (2001), when the WBC is strong, it takes the leaping path so that the vorticity balance is between meridional advection term and beta term. When the WBC is weak, it intrudes into the western basin so that the vorticity balance is between the beta term and the zonal advection term (Yuan and Wang 2011). In this subsection, we first examine the vorticity analysis of the WBC at the steady state to disclose the WBC bifurcation dynamics; then, we analyze the vorticity balance for the WBC at the critical eddy shedding-leaping state. The vorticity balances at the grid point nearest to the point $X_{P}$ for the $\mathrm{WBC}$ in the eddy-shedding and leaping regimes are evaluated, respectively. To calculate all vorticity terms, the vorticity equation is first derived from the cross-differentiation forms of the momentum equations in (1) as follows: 

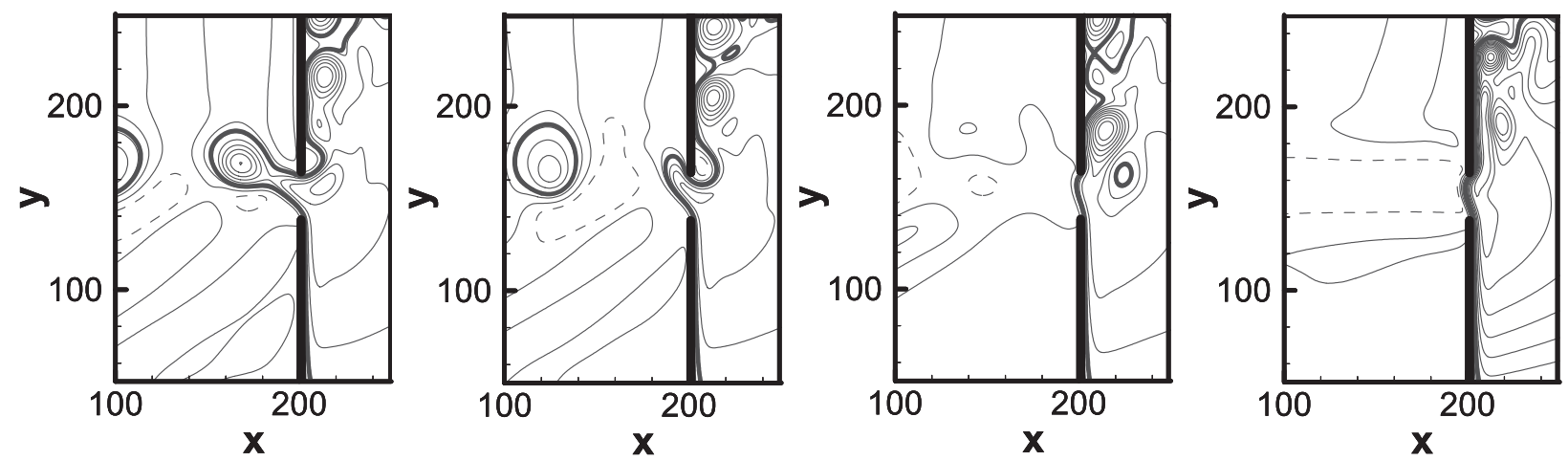

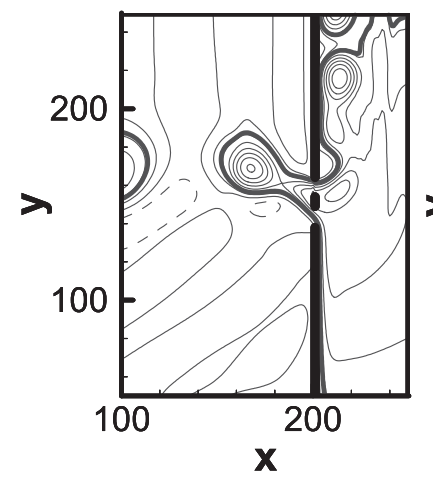

Day 0

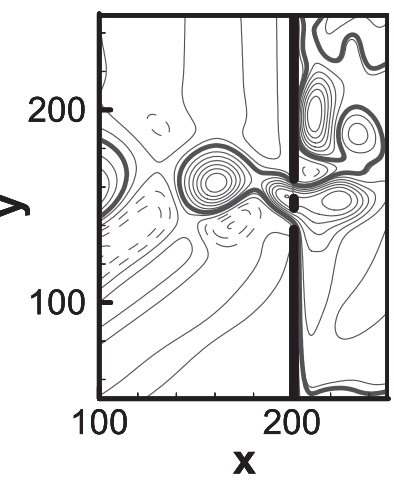

Day 1100

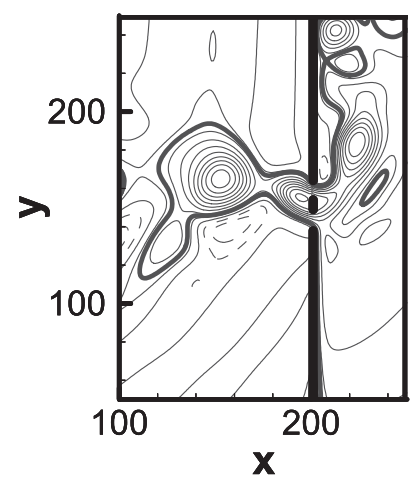

Day 1200

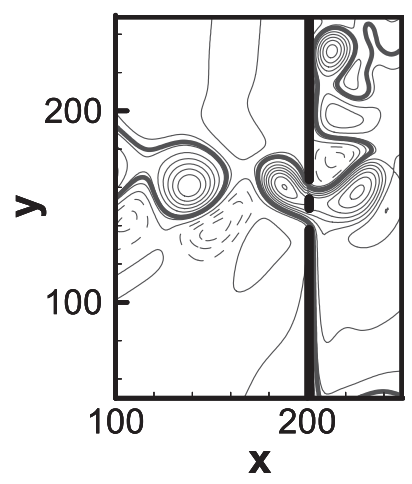

Day 4000

FIG. 4. (top) The time evolution of WBC flow pattern at $\mathrm{Re}=65$ for Exp A1, corresponding to the $R_{L, n}$ point in Fig. 2, where the initial solution is obtained from the steady solution of the WBC without an island in the gap at $\mathrm{Re}=64$. (bottom) As in the top panels, but inserting an island in the middle of the gap at day 0 for Exp A2.

$$
\zeta_{t}+J(\psi, \zeta)+\beta \psi_{x}=A_{h} \nabla^{2} \zeta-R \zeta+\operatorname{curl}\left(\frac{\tau}{\rho_{0} h}\right)
$$

where $\zeta=\nabla^{2} \psi$ is the relative vorticity and $\psi$ is the streamfunction. Note that the point $X_{P}$ is located to the west of the gap, and the wind field is added to the eastern basin only in the numerical experiment, so the last term in (4) vanishes in the following vorticity analysis. Due to the particularity of the point $X_{P}$, the zonal advection term in the vorticity equation is very small and the inertia term is dominated by the meridional advection term. All terms are moved to the left-hand side of the equation for extracting each vorticity balance term.

The beta term is balanced by the other terms in the vorticity equation for the WBC in the eddy -shedding regime (Fig. 6, top), while the meridional advection term is balanced by beta and viscosity terms for the WBC in the leaping regime (Fig. 6, bottom), regardless of the island being present or not. The results show that there is no difference in terms of the vorticity balance of the WBC in the steady state, with and without the island. When the WBC is translated from the eddy-shedding to the leaping regime, all vorticity balance terms are translated from the periodic state to the steady state of the curves, as shown in Fig. 6, and vice versa. The vorticity balance analysis illustrates the WBC with the island in the gap experiences similar bifurcation change as that without the island, which was investigated by Sheremet (2001).

The hysteresis curves, however, show that presence of the island indeed enlarges the range of the Reynolds number in the eddy-shedding regime, as shown in Fig. 2. To better understand the impact of the island on WBC paths in this dynamic system, vorticity balance analysis during the transition stage of the WBC for Exps $\mathrm{A} 1-\mathrm{A} 2$ and $\mathrm{B} 1-\mathrm{B} 2$ is carried out, and results are compared to disclose the regime dynamics during the hysteresis evolution process.

At the beginning of Exp A1 (Fig. 7, top left), the WBC sheds eddies periodically, and the vorticity balance near the point $X_{P}$ is mainly the beta term versus the other terms. The time evolution of the vorticity balance then shows the meridional advection term increases, and the beta and viscosity terms both increase to balance the meridional advection term around day 1200 . The result is similar to that shown in Fig. 3 of Yuan and Wang (2011), 

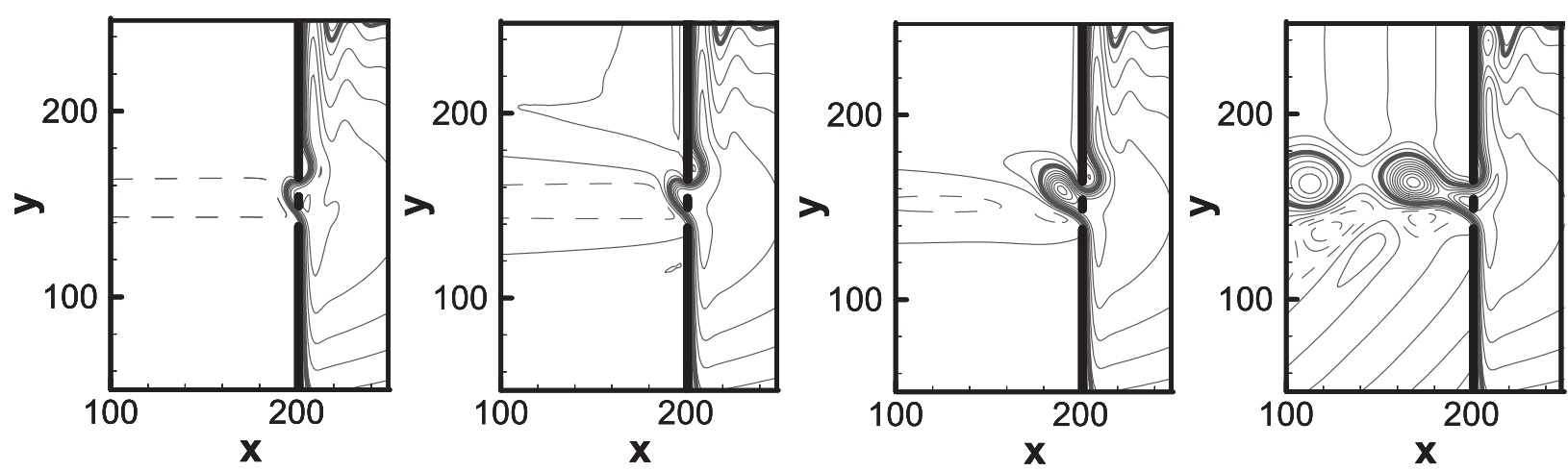

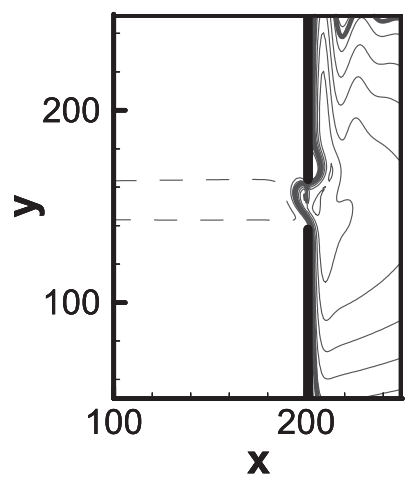

Day 0

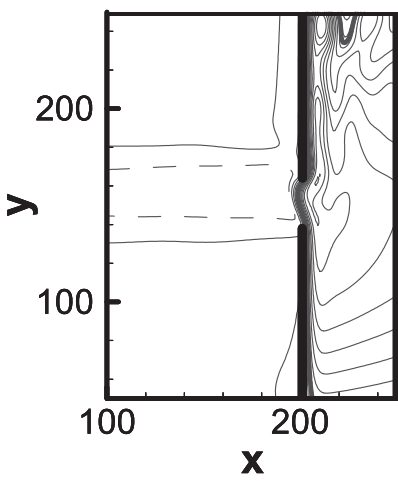

Day 500

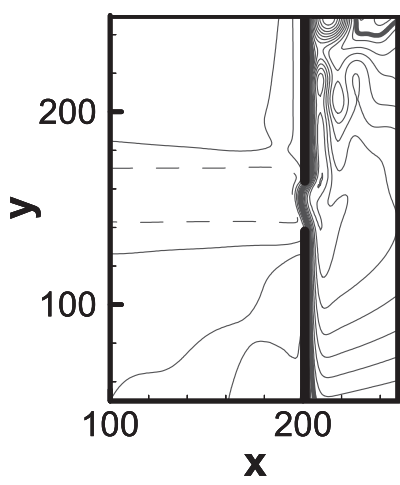

Day 600

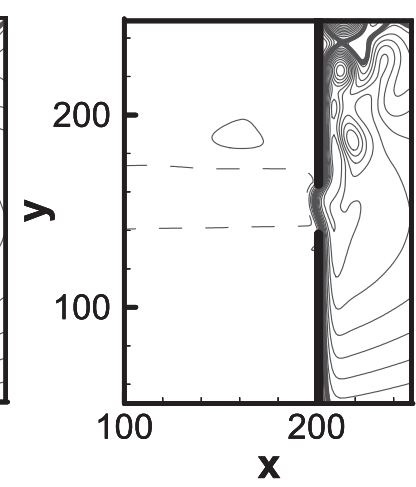

Day 1000

FIG. 5. (top) As in Fig. 4, but for Exp B1 at Re $=50$, corresponding to the $R_{P, i}$ point in Fig. 2, where the initial solution is obtained from the steady solution of the WBC with an island in the middle of the gap at $\mathrm{Re}=51$. (bottom) The island is removed at day 0 in Exp B2, and the time evolution of the WBC flow pattern for Exp B2 is shown.

except for the difference that the enhancement of meridional advection term in their experiment was induced by mesoscale eddy-WBC interaction, while that in Exp A1 is induced by the increased wind stress. The hysteresis curve in Fig. 2 suggests that the WBC without the island stays in the leaping regime and an irreversible transition of WBC path occurs after the Reynolds number exceeds $\operatorname{Re}=66$. When the island is inserted into the gap at day 0 in $\operatorname{Exp}$ A2, the vorticity balance near the point $X_{P}$ is mainly the beta term versus the other terms. All the vorticity balance terms maintain quasi periodicity as the time elapses, and the WBC stays in the eddy-shedding regime (Fig. 7, top right). The vorticity balance near the point $X_{P}$ for Exp B1 and that for Exp B2 are shown in Fig. 7 (bottom). At the early stage of Exp B1, the WBC stays in the leaping regime, and vorticity balance shows meridional advection term is balanced by both beta and viscosity terms. Then, the decreased wind stress leads to an enhancement of the local-rate-of-change term and to reductions of meridional advection term, beta term, and viscosity term. The vorticity balance is mainly the beta term versus the other terms after day 500. At this time, the WBC translates from the leaping to the periodic eddy-shedding regime (Fig. 7, bottom left). In Exp B2, the vorticity balance among meridional advection term, beta term, and viscosity term remains nearly the same for the remainder of the integration (Fig. 7, bottom right). The WBC stays in the leaping regime.

The vorticity balance analysis dynamically explains the WBC transition at the critical state. To illustrate the role of the island in the experiments, Fig. 8 shows the anomalous flow fields and the anomalous currents of Exp A2 minus Exp A1. We can see an anomalous cyclonic eddy and anomalous southward current east of the southern edge of the gap induced by the friction and the blocking effect of the inserted island in Exp A2 before (Fig. 8, top) and after (Fig. 8, bottom) the transition of the WBC path occurs. The anomalous southward current reduces the northward current and the meridional advection of the WBC into the gap circulation at the entrance, which explains the phenomenon of the WBC continuing to shed eddies when the island is inserted in Exp A2. Contrarily, when the island is removed from Exp B2, the absence of the friction of the island leads to an anomalous northward current, which 

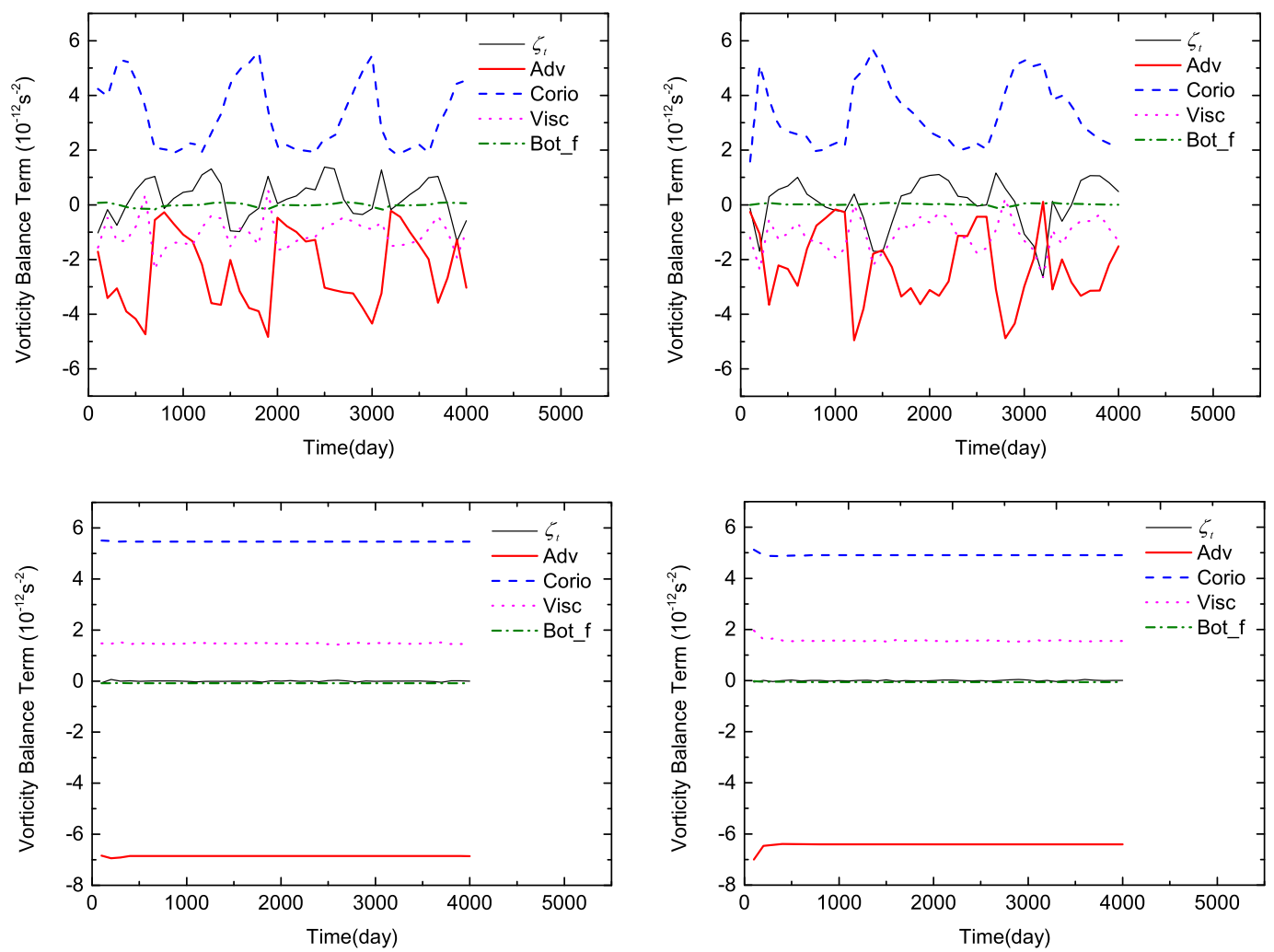

FIG. 6. (top) Vorticity balance terms near the $X_{P}$ point for the steady-state WBC (left) without an island at $\mathrm{Re}=64$ and (right) with an island at $\mathrm{Re}=73$ in the wind-stress-increasing stage (eddy-shedding path). (bottom) Vorticity balance terms for the steady state $\mathrm{WBC}$ (left) without an island at $\mathrm{Re}=47$ and (right) with an island at $\operatorname{Re}=51$ in the wind-stress-decreasing stage (leaping path).

enhances the meridional advection of the WBC at the entrance and induces the WBC continuing to leap across the gap (not shown).

\section{Impacts of island size and location on WBC paths}

In this section, we study the effects of island's northsouth size and north-south or east-west location on WBC bifurcation (see Table 1).

First, numerical experiments are examined for the WBC bifurcation with an island of various north-south sizes in the middle of the gap. For simplicity, the steady state of the WBC is obtained by integrating the model from motionless ocean in the two basins for each $\alpha_{\tau}$. Three types of WBC paths are found in these numerical experiments: the penetration path with an anticyclonic loop $(\mathrm{P})$, the periodic eddy-shedding path $(\mathrm{E})$, and the leaping path $(\mathrm{L})$. Two types of transition processes between different WBC paths are obtained, namely, P-to-E and E-to-L paths.

The width of the gap plays an important role in the bifurcation of the WBC, as in Sheremet (2001). Hereon, the influence of increasing gap width on the transition process of the WBC is studied for a gap-leaping system with an island of fixed north-south size $(\sim 56 \mathrm{~km})$ in the middle of the gap (defined as Exp-G set). To compare with the results in Sheremet (2001), Fig. 9 shows the critical Re as a function of $\lambda_{1}$, where $\lambda_{1}=L_{s} / L_{M}$ and $L_{s}$ is the distance between the tip of the southern barrier and the southern tip of the island. We can see that the critical Reynolds numbers for both the P-to-E process $\left(R e_{P E}\right)$ and the E-to-L process $\left(R_{E L}\right)$ increase as the gap width is widened, which exhibits similar characteristics as the results in Sheremet (2001), even though there was no island in his study.

Next, we fix the total gap width, and investigate the influence of various island north-south sizes on WBC bifurcation (defined as Exp-I set). Here, the width of the southern gap $L_{s}$ is set to equal to the width of the northern gap $L_{n}$, which is between the tip of the northern barrier and the northern tip of the island. Figure 10 shows the critical $\mathrm{Re}$ as a function of $\lambda_{2}$, where $\lambda_{2}=\left(L_{i} / 2\right) / L_{s}$, and $L_{i}$ is the north-south width of the island. We can see that the impact of island north-south size on the Hopf bifurcation of the WBC is negligible $\left(\mathrm{Re}_{\mathrm{PE}}\right)$. However, the island promotes the WBC to shed 

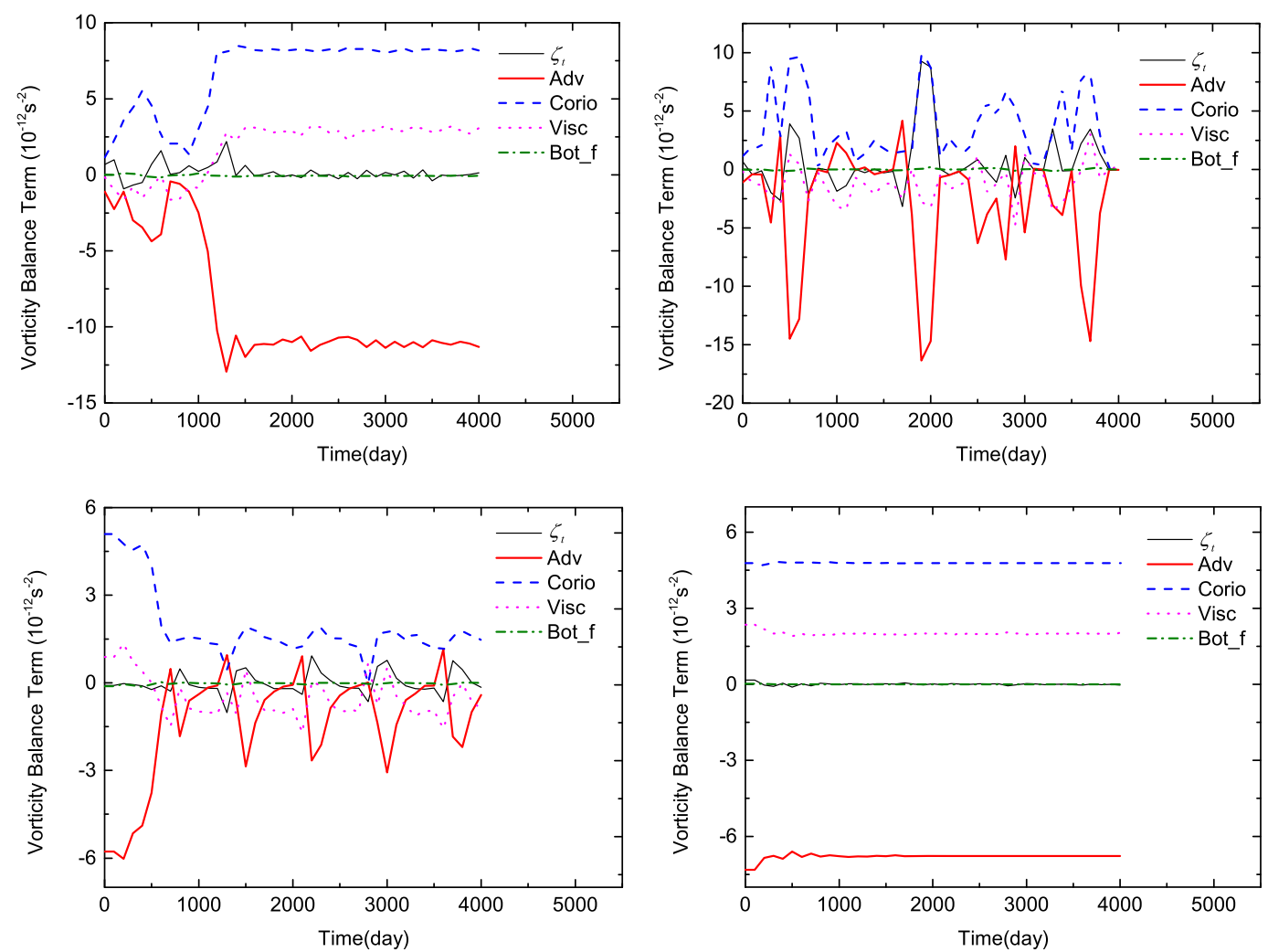

FIG. 7. Vorticity balances for (top left) Exp A1 and (top right) Exp A2 at Re $=65$ and for (bottom left) Exp B1 and (bottom right) Exp B2 at $\mathrm{Re}=50$.

eddy for a relatively larger Re in the E-to-L process $\left(\operatorname{Re}_{\mathrm{EL}}\right)$ compared with the no-island case $\left(\lambda_{2}=0\right)$. Moreover, the larger the island size is, the easier the eddy shedding becomes. It is the fact that the width of the southern gap is decreased as the island north-south size is increased in Exp-I set, so $\mathrm{Re}_{\mathrm{EL}}$ is inversely proportional to $L_{s}$. The result is opposite to the finding in Sheremet (2001), where his $\mathrm{Re}_{\mathrm{P}}$ is proportional to the half-width of the gap. We suspect that the existence of the island changes the characteristics of the gap system, because the island facilitates the WBC intrusion as shown in section 3. In addition, more experiments are designed for longer island cases with $\lambda_{2} \in[0.39,0.62]$; however, the leaping path of the WBC is not found (not shown) and the gap is always "leaky." So the half-width of the island should be confined to be small compared with the width of the southern gap $\left(\lambda_{2} \leq 0.31\right.$ in Fig. 10), according to the practicality that the Kuroshio passes across the Luzon Strait in this study.

As the north-south size of the island can change the width of the gap in these experiments, we then investigate the influence of island north-south size on WBC bifurcation when the gap width is enlarged accordingly (defined as Exp-GI set). Here, $L_{s}$ and $L_{n}$ are fixed and equal. In Exp-GI set, the widths of the southern and northern gaps segments are enlarged relative to those in Exp-I set that has a fixed total gap width. Figure 11 shows the critical $\mathrm{Re}$ as a function of $\lambda_{3}$, where $\lambda_{3}=L_{i} / L_{g}$ and $L_{g}$ is the total gap width between the two barriers. We can see that the critical values for both the P-to-E process $\left(\mathrm{Re}_{\mathrm{PE}}\right)$ and E-to-L process $\left(\mathrm{Re}_{\mathrm{EL}}\right)$ increase as the total gap width and island north-south size increase, and are both larger than those in Fig. 9.

Second, we study the effect of island north-south or east-west location on WBC bifurcation. Here, we fix the island north-south width to be $56 \mathrm{~km}$ and the gap width to be $290 \mathrm{~km}$. The influence of the north-south location of the island on the WBC bifurcation is examined first (defined as Exp-NS set). The critical Re for the WBC transition in P-to-E process and that in E-to-L process as a function of $\lambda_{4}\left(=L_{s} / L_{g}\right)$ are plotted in Fig. 12 (top). The results show that the north-south location of the island in the gap has almost no impact on the Hopf bifurcation of the $\mathrm{WBC}\left(\mathrm{Re}_{\mathrm{PE}}\right)$. However, the $\mathrm{Re}_{\mathrm{EL}}$ curve rises quickly at first and then falls drastically in Exp-NS set. When $\lambda_{4}$ is less than 0.58 , the island promotes the WBC to shed eddy compared with the no-island case (the dashed line represents the critical Reynolds number 

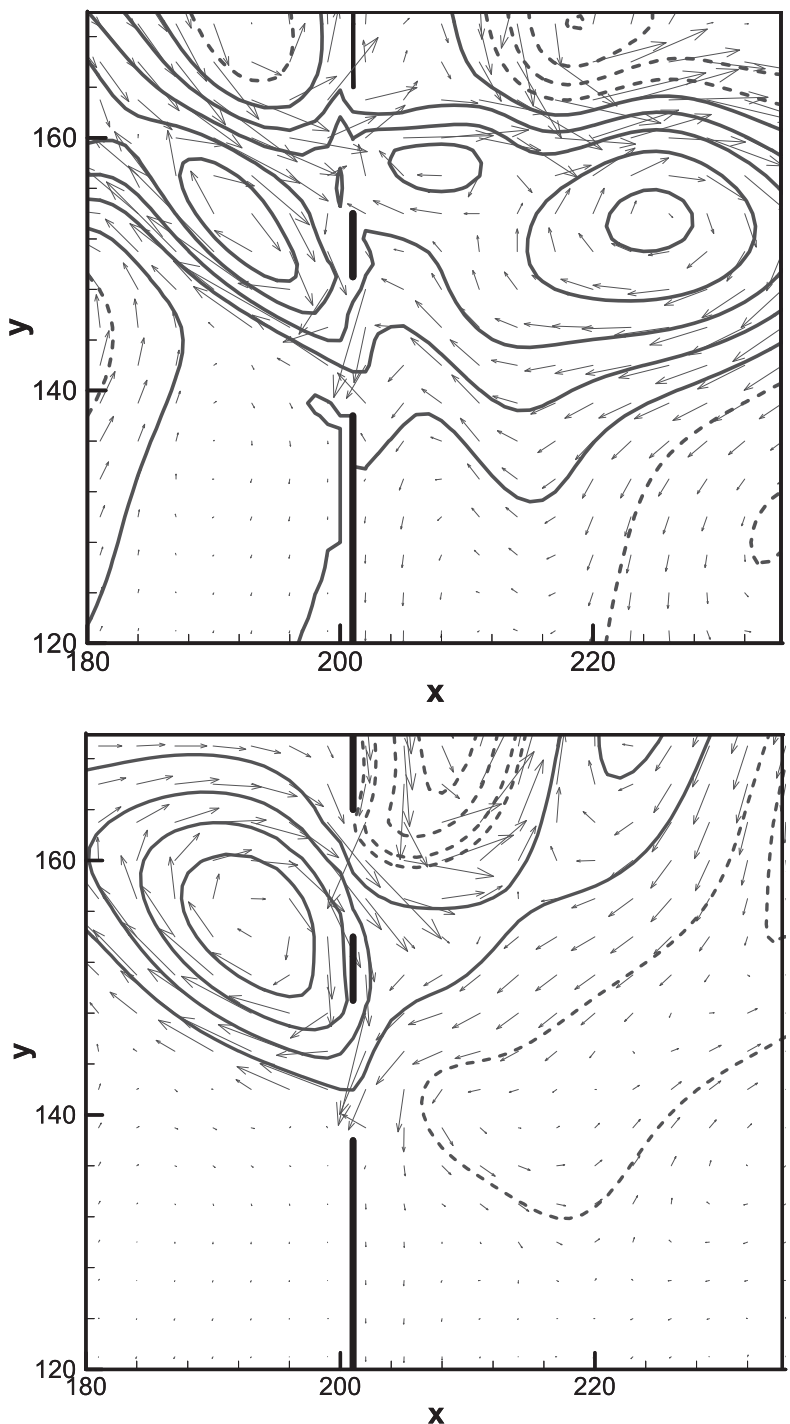

FIG. 8. Anomalous flow field (contours) and anomalous currents (arrows) of Exp A2 minus Exp A1 at (top) day 1100 and (bottom) day 1200 .

in the E-to-L process of the no-island case). When $\lambda_{4}$ exceeds 0.58 , the critical Re becomes less than that of the no-island case, which illustrates the WBC is hindered to shed eddy when the island becomes extremely close to the tip of the northern barrier compared with the no-island case. As for the cases of $\lambda_{4}<0.23$, the WBC is found to be translated directly from the steady anticyclonic loop pattern to the leaping pattern. The periodic eddy-shedding state is not found in these numerical experiments.

The influence of the east-west location of the island on WBC bifurcation is examined in Exp-WE set (Fig. 12, bottom). The zonal distance $L_{\mathrm{W}-\mathrm{E}}$ between the island and the gap is nondimensionalized as $\lambda_{5}=L_{\mathrm{W}-\mathrm{E}} / L_{M}$; the

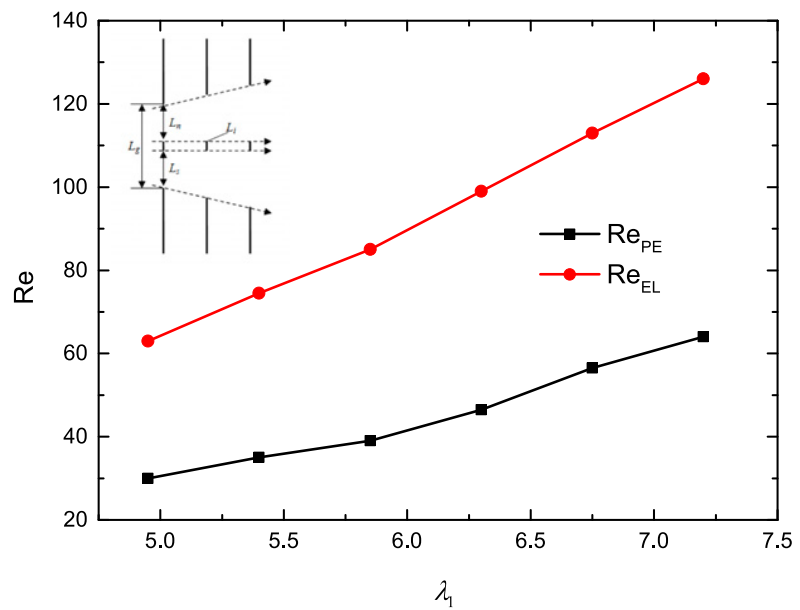

FIG. 9. Critical Re as a function of $\lambda_{1}\left(=L_{s} / L_{M}\right)$ with a fixed north-south size of the island for Exp-G set. $\mathrm{Re}_{\mathrm{PE}}$ and $\mathrm{Re}_{\mathrm{EL}}$ represent the critical values for the transition of the WBC in the P-to-E process and the E-to-L process, respectively. The schematic of various gap widths is shown at the top left of the figure.

positive (negative) value represents the island is to the east (west) of the gap. The Hopf bifurcation of the WBC is almost not sensitive to the east-west location of the island $\left(\mathrm{Re}_{\mathrm{PE}}\right)$. The $\mathrm{Re}_{\mathrm{EL}}$ curve for the WBC in E-to-L process shows that the island promotes the WBC to shed eddy compared with the no-island case (the dashed line in Fig. 12, bottom). Moreover, the influence of the eastward-shifted island on the WBC transition from the periodic eddy-shedding to the leaping regime is gradually reduced as $\lambda_{5}$ increases. In particular, when the zonal distance of the eastward-shifted island from the gap exceeds the width of the Munk layer $\left(\lambda_{5}>1\right)$, the influence of the eastward-shifted island on the WBC in the E-to-L process can be ignored.

\section{Summary and discussion}

In this paper, the hysteresis of the WBC without an island in the gap is reexamined using an idealized, nonlinear 1.5-layer ocean model with two basins, and the influence of an island in the gap (closer to the Luzon Strait case) on the hysteresis and bifurcation dynamics of the WBC is investigated. The results in Fig. 2 show that the hysteresis and multiple states exist for the WBC with and without an island in the middle of the gap. The steady leaping path and the periodic eddy-shedding path of the WBC, which are determined by the historical WBC evolution, can coexist for the same Reynolds number. The results of hysteresis indicate that the critical Re (from the periodic eddy-shedding to the leaping regime) for the WBC with the island in the middle of the gap is larger than that without. Also, the WBC in the 


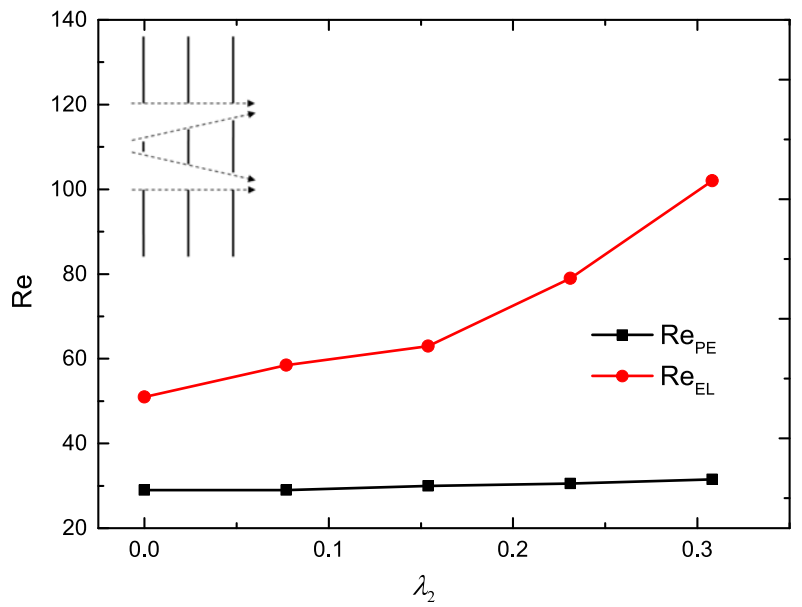

FIG. 10. Critical Re as a function of $\lambda_{2}\left[=\left(L_{i} / 2\right) / L_{s}\right]$ with a constant total gap width $L_{g}$ for Exp-I set. Re $\mathrm{P}_{\mathrm{PE}}$ and $\mathrm{Re} \mathrm{EL}_{\mathrm{EL}}$ represent the critical values for the transition of the WBC in the P-to-E process and the E-to-L process, respectively. The schematic of various north-south sizes of the island is shown at the top left of the figure.

leaping regime can shed eddy more easily with the island in the middle of the gap than without. The island in the middle of the gap facilitates the WBC intrusion into the western basin by shedding eddies. The dynamics behind the island's impact on the WBC transition is explained by vorticity balance of the WBC at critical eddy shedding-leaping state.

The vorticity balance analysis illustrates that the WBC with the island experiences similar bifurcation change in the steady state solution as in the no-island case. At the critical eddy shedding-leaping state of the WBC, the inserted (removed) island promotes the WBC to continue to shed eddy (leap across the gap) when the transition of the WBC path from the periodic penetrating (leaping) to the leaping (periodic penetrating) regime occurs. Then, the vorticity balance shows that increased meridional advection induces the WBC transition from the periodic eddy-shedding to the leaping regime, and vice versa.

The critical $\mathrm{Re}_{\mathrm{PE}}$ and $\mathrm{Re}_{\mathrm{EL}}$ values both increase as the total gap width is widened with an island of fixed width. The Hopf bifurcation of the WBC is not sensitive to the island's north-south size with the total gap width is fixed. The $\mathrm{Re}_{\mathrm{EL}}$ value is increased as the island's north-south size is increased. Moreover, the critical $\mathrm{Re}_{\mathrm{PE}}$ and $\mathrm{R} \mathrm{e}_{\mathrm{EL}}$ values both increase when the island's north-south size and the gap width are increased simultaneously. The Hopf bifurcation of the WBC is not sensitive to the island's north-south or east-west location in the model. Furthermore, the island promotes the WBC to shed eddy except when it is located close to the northern barrier. The influence of the eastward-shifted island on

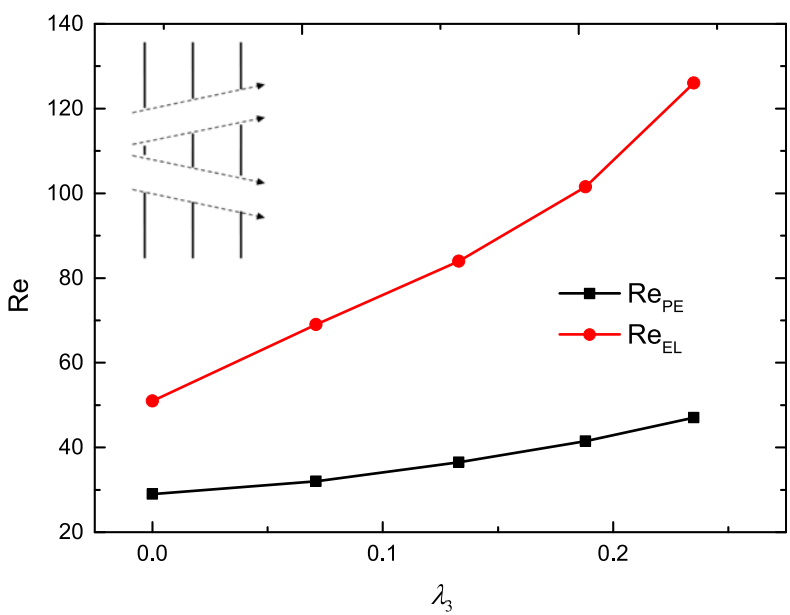

FIG. 11. Critical Re as a function of $\lambda_{3}\left(=L_{i} / L_{g}\right)$ with constant southern and northern gap widths in Exp-GI set. The north-south size of the island and the total gap width are increased simultaneously. $\mathrm{Re}_{\mathrm{PE}}$ and $\mathrm{Re}_{\mathrm{EL}}$ represent the critical values for the transition of the WBC in the P-to-E process and the E-to-L process, respectively. The schematic of various gap widths and island's north-south sizes is shown at the top left of the figure.

the WBC in the E-to- $\mathrm{L}$ process is gradually reduced when its zonal distance from the gap exceeds the width of the Munk layer compared to the no-island case.

These results may be applied to the situation when the Kuroshio passes by the Luzon Strait. As mentioned in Yuan and Wang (2011), observations illustrate that the Kuroshio leaping across the gap is about twice as often as the Kuroshio penetrating into the SCS in the anticyclonic eddy-shedding regime. Their numerical experiments showed that the chance and duration for the Kuroshio to leap across the Luzon Strait is about 3 times as often as to penetrate into the SCS in an anticyclonic loop when the WBC is perturbed by the mesoscale eddy from the eastern basin. Their results also showed that the chance and time for the WBC in the leaping regime based on their numerical experiments are a little longer than the observation. However, the effect of the island is not considered in their idealized model. In this study, we use numerical experiments to quantitatively compare the critical Re for the transitions of the WBC with and without an island in the gap. Our conclusion is that the island promotes the WBC to penetrate into the western basin regardless of the size and location of the island except when the island is located too close to the northern barrier. Qualitatively, it is the impact of the island leading to the WBC staying in the penetrating regime for a longer time compared with the result of Yuan and Wang (2011). Future work is needed to study quantitatively the impingement of mesoscale eddies on the WBC with an island in the gap and to confirm whether or not the WBC is more likely to 

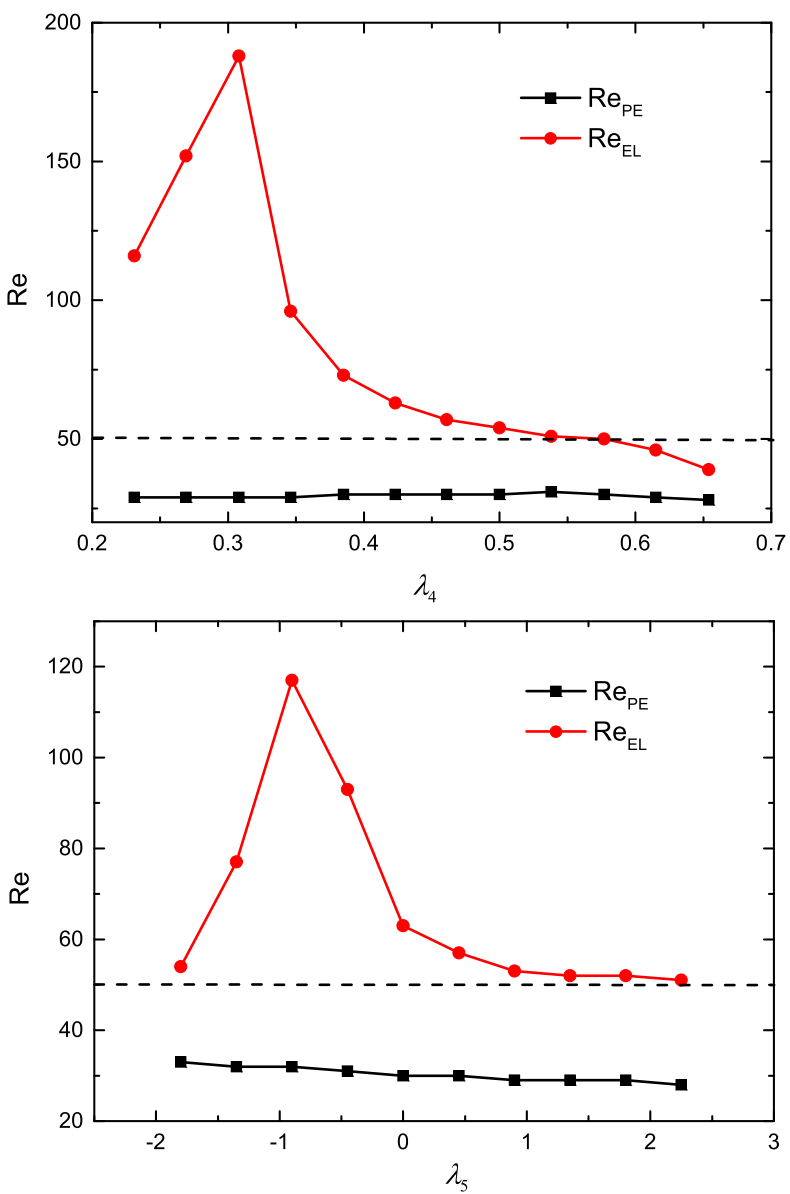

FIG. 12. Critical Re as a function of (top) $\lambda_{4}\left(=L_{s} / L_{g}\right)$ and (bottom) $\lambda_{5}\left(=L_{\mathrm{W}-\mathrm{E}} / L_{M}\right)$. The dashed line represents the critical value of the WBC without an island in the gap in the E-to-L process.

penetrate into the western basin and last longer time under the influence of an island.

The WBC transport (Sheremet 2001), mesoscale eddy (Yuan and Wang 2011), and monsoon (Wang et al. 2010) have been found to induce WBC transition. However, the large-scale circulation driven by the monsoon in the western basin may also affect the WBC flow pattern. Intuitively, this circulation should push the WBC to hinder its intruding into the western basin. What the dynamics of the two kinds of large-scale circulations' interaction are and what the impact of an island in the dynamic gap-leaping system is are all worthy studying.

Acknowledgments. This research is supported by the Natural Science Foundation of China (41706003, 41522601, and 41776004), the China Postdoctoral Science Foundation (2017M621604), and the Fundamental Research Funds for the Central Universities (2017B04114, 2017B04314, 2016B11614, and 2019B18714). The authors thank
Dr. D.L. Yuan and Dr. Z. Wang for their helpful suggestions and the two anonymous reviewers for their many constructive comments. Dr. Zuojun Yu helped to improve the presentation greatly.

\section{REFERENCES}

Andres, M., and C. Cenedese, 2013: Laboratory experiments and observations of cyclonic and anticyclonic eddies impinging on an island. J. Geophys. Res. Oceans, 118, 762-773, https:// doi.org/10.1002/jgrc.20081.

Caruso, M. J., G. G. Gawwarkiewicz, and R. C. Beardsley, 2006: Interannual variability of the Kuroshio intrusion in the South China Sea. J. Oceanogr., 62, 559-575, https://doi.org/10.1007/ s10872-006-0076-0.

Cenedese, C., 2002: Laboratory experiments on mesoscale vortices colliding with a seamount. J. Geophys. Res., 107, 3053, https:// doi.org/10.1029/2000JC000599.

— C. Adduce, and D. M. Fratantoni, 2005: Laboratory experiments on mesoscale vortices interacting with two islands. J. Geophys. Res., 110, C09023, https://doi.org/10.1029/ 2004JC002734.

Chelton, D. B., R. A. DeSzoeke, M. G. Schlax, K. El Naggar, and N. Siwertz, 1998: Geographical variability of the firstbaroclinic Rossby radius of deformation. J. Phys. Oceanogr., 28, 433-460, https://doi.org/10.1175/1520-0485(1998) 028<0433:GVOTFB $>2.0 . \mathrm{CO} ; 2$.

Cheng, X. H., J. P. McCreary, B. Qiu, Y. Q. Qi, and Y. Du, 2017: Intraseasonal-to-semiannual variability of sea-surface height in the eastern, equatorial Indian Ocean and southern Bay of Bengal. J. Geophys. Res. Oceans, 122, 4051-4067, https:// doi.org/10.1002/2016JC012662.

Chern, C.-S., and J. Wang, 1998: A numerical study of the summertime flow around the Luzon Strait. J. Oceanogr., 54, 53-64, https://doi.org/10.1007/BF02744381.

Fang, G. H., W. D. Fang, Y. Fang, and K. Wang, 1998: A survey of studies on the South China Sea upper ocean circulation. Acta Oceanogr. Taiwan., 37, 1-16.

Herbette, S., Y. Morel, and M. Arhan, 2003: Erosion of a surface by a seamount. J. Phys. Oceanogr., 33, 1664-1679, https:// doi.org/10.1175/2382.1.

Hu, J. Y., K. Hiroshi, H. S. Hong, and Y. Q. Qi, 2000: A review on the currents in the South China Sea: Seasonal circulation, South China Sea warm current and Kuroshio intrusion. J. Oceanogr., 56, 607-624, https://doi.org/10.1023/ A:1011117531252.

Kuehl, J., and V. A. Sheremet, 2009: Identification of a cusp catastrophe in a gap-leaping western boundary current. $J$. Mar. Res., 67, 25-42, https://doi.org/10.1357/002224009788597908.

$\longrightarrow$, and —, 2014: Two-layer gap-leaping oceanic boundary currents: Experimental investigation. J. Fluid Mech., 740, 97113, https://doi.org/10.1017/jfm.2013.645.

Lu, J., and Q. Liu, 2013: Gap-leaping Kuroshio and blocking westward-propagating Rossby wave and eddy in the Luzon Strait. J. Geophys. Res. Oceans, 118, 1170-1181, https:// doi.org/10.1002/jgrc.20116.

Metzger, E. J., and H. E. Hurlburt, 2001: The importance of high horizontal resolution and accurate coastline geometry in modeling South China Sea inflow. Geophys. Res. Lett., 28, 1059-1062, https://doi.org/10.1029/2000GL012396.

Nan, F., Z. He, H. Zhou, and D. Wang, 2011: Three long-lived anticyclonic eddies in the Northern South China Sea. 
J. Geophys. Res., 116, C05002, https://doi.org/10.1029/ $2010 \mathrm{JC} 006790$.

, H. J. Xue, and F. Yu, 2015: Kuroshio intrusion into the South China Sea: A review. Prog. Oceanogr., 137, 314-333, https:// doi.org/10.1016/j.pocean.2014.05.012.

Nitani, H., 1972: Beginning of the Kuroshio. Kuroshio: Its Physical Aspects of the Japan Current., H. Stommel and K. Yashida, Eds., University of Tokyo Press, 129-163.

Qiu, B., and S. Chen, 2012: Multidecadal sea level and gyre circulation variability in the northwestern tropical Pacific Ocean. J. Phys. Oceanogr., 42, 193-206, https://doi.org/ 10.1175/JPO-D-11-061.1.

Qu, T. D., H. Mitsudera, and T. Yamagata, 2000: Intrusion of the North Pacific waters into the South China Sea. J. Geophys. Res., 105, 6415-6424, https://doi.org/10.1029/1999JC900323.

, Y. Y. Kim, M. Yaremchuk, T. Tozuka, A. Ishida, and T. Yamagata, 2004: Can Luzon Strait transport play a role in conveying the impact of ENSO to the South China Sea? J. Climate, 17, 3644-3657, https://doi.org/10.1175/ 1520-0442(2004)017<3644:CLSTPA > 2.0.CO;2.

Sheremet, V. A., 2001: Hysteresis of a western boundary current leaping across a gap. J. Phys. Oceanogr., 31, 1247-1259, https://doi.org/10.1175/1520-0485(2001)031<1247:HOAWBC> 2.0.CO;2.

—_, and J. Kuehl, 2007: Gap-leaping western boundary current in a circular tank model. J. Phys. Oceanogr., 37, 1488-1495, https://doi.org/10.1175/JPO3069.1.

Simmons, H. L., and D. Nof, 2002: The squeezing of eddies through gaps. J. Phys. Oceanogr., 32, 314-335, https://doi.org/10.1175/ 1520-0485(2002)032<0314:TSOETG $>2.0$. CO 2 .

Sun, R. L., G. H. Wang, and C. L. Chen, 2016: The Kuroshio bifurcation associated with islands at the Luzon Strait. Geophys. Res. Lett., 43, 5768-5774, https://doi.org/10.1002/2016GL069652.

Wang, Z., and D. Yuan, 2012: Nonlinear dynamics of two western boundary currents colliding at a gap. J. Phys. Oceanogr., 42, 2030-2040, https://doi.org/10.1175/JPO-D-12-05.1.

- , and -2014 : Multiple equilibria and hysteresis of two unequal-transport western boundary currents colliding at a gap. J. Phys. Oceanogr., 44, 1873-1885, https://doi.org/10.1175/ JPO-D-13-0234.1.

,$- \ldots$, and Y. Hou, 2010: Effect of meridional wind on gapleaping western boundary current. Chin. J. Oceanol. Limnol., 28, 354-358, https://doi.org/10.1007/s00343-010-9281-1.

Wu, C.-R., 2013: Interannual modulation of the Pacific Decadal Oscillation (PDO) on the low-latitude western North Pacific. Prog. Oceanogr., 110, 49-58, https://doi.org/10.1016/ j.pocean.2012.12.001.

Xiu, P., F. Chai, L. Shi, H. J. Xue, and Y. Chao, 2010: A census of eddy activities in the South China Sea during 1993-2007. J. Geophys. Res., 115, C03012, https://doi.org/10.1029/ 2009JC005657.

Yu, Z. J., S. Shen, J. P. McCreary, M. Yaremchuk, and R. Furue, 2007: South China Sea throughflow as evidenced by satellite images and numerical experiments. Geophys. Res. Lett., 34, L01601, https://doi.org/10.1029/2006GL028103

Yuan, D. L., and R. X. Li, 2008: Dynamics of eddy-induced Kuroshio variability in Luzon Strait (in Chinese with English abstract). J. Trop. Oceanogr., 27, 1-9.

— Boundary Current flowing by a gap forced by impingement of mesoscale eddies. J. Phys. Oceanogr., 41, 878-888, https:// doi.org/10.1175/2010JPO4489.1.

—_, W. Han, and D. Hu, 2006: Surface Kuroshio path in the Luzon Strait area derived from satellite remote sensing data. J. Geophys. Res., 111, C11007, https://doi.org/10.1029/ 2005JC003412.

Zhang, Z. W., W. Zhao, B. Qiu, and J. W. Tian, 2017: Anticyclonic eddy shedding from Kuroshio Loop and the accompanying cyclonic eddy in the northeastern South China Sea. J. Phys. Oceanogr., 47, 1243-1259, https://doi.org/10.1175/ JPO-D-16-0185.1.

Zhong, L. H., L. Hua, and D. Luo, 2016: The eddy-mean flow interaction and the intrusion of western boundary current into the South China Sea-type basin in an idealized model. J. Phys. Oceanogr., 46, 2493-2527, https://doi.org/10.1175/ JPO-D-15-0220.1. 